\title{
MAGALHÃES, I.; MARTINS, A. R.; RESENDE, V. DE M. ANÁLISE DE DISCURSO CRÍTICA: UM MÉTODO DE PESQUISA QUALITATIVA. BRASÍLIA: EDITORA DA UNIVERSIDADE DE BRASÍLIA, 2017. 260P.
}

\section{Girlane Maria Ferreira Florindo*}

A Análise de Discurso Crítica, doravante $\mathrm{ADC}$, não se apresenta como uma teoria única, tampouco uma metodologia específica. No quadro desses debates teóricos, e também metodológicos, a interdisciplinaridade, e mesmo a transdisciplinaridade, se mostra como uma das características comuns a diferentes abordagens em ADC. Todas essas abordagens favorecem um diálogo entre as correntes do funcionalismo linguístico e as disciplinas das Ciências Humanas e Sociais. Os estudos em ADC, diversificados e orientados por diferentes dados e metodologias, preocupam-se com a relação linguagem e sociedade, em uma articulação apta à produção de uma crítica social.

Análise de discurso crítica: um método de pesquisa qualitativa, de Izabel Magalhães, André Ricardo Martins e Viviane de Melo Resende é uma obra voltada para a Análise de Discurso Crítica, particularmente na perspectiva da Abordagem Dialético-Relacional de Norman Fairclough, cujo foco é a relação dialética entre discurso e mudança social. Os autores são grandes expoentes desse campo teórico, com destaque para a linguista Izabel Magalhães $(2004,2005,2010,2016)$, pioneira em "empunhar a bandeira" da ADC no Brasil, conforme palavras de Kanavillil Rajagopalan no prefácio do volume 6 da Coleção Linguagem e Sociedade (2013). No campo da ADC, portanto, a obra não é se apresenta como um estudo introdutório, sendo recomendadas outras leituras como Ramalho e Resende (2006), Resende e Ramalho (2011).

Como apontam o título da obra e a introdução, o livro volta-se para questões metodológicas, no que se refere ao campo de estudo da Análise de Discurso Crítica. A obra é constituída de três partes e uma conclusão; cada parte é composta de três capítulos subdivididos em seções e respectivas considerações finais, assim nomeadas: Parte 1: Um método de pesquisa qualitativa para a crítica social ${ }_{i}$ Parte 2: Análise de Discurso Crítica e etnografia; e Parte 3: Um método de análise textual.

\footnotetext{
* Universidade de Brasília (UnB), Brasília, DF, Brasil. girlane.florindo@ifb.edu.br 
A parte 1 apresenta a relação da pesquisa qualitativa e da crítica social com a Análise de Discurso Crítica. Os autores discorrem, então, sobre a rede que se forma com interligação entre práticas sociais e práticas teóricas, que, no que se refere à atuação dos acadêmicos, podem estar adotando uma conduta crítica ou omissa na definição de suas questões de investigação. Se o pesquisador ou a pesquisadora adota uma postura crítica, a ADC é a abordagem teórico-metodológica indicada. Em seguida, os autores procuram esclarecer como o estudo do discurso e da semiose podem contribuir para a crítica a problemas sociais apontando as considerações e conceituações de Fairclough acerca do discurso e de suas influências sobre o processo da globalização. A consideração de fatores socioculturais, econômicos, políticos e outros é adequada ao método de pesquisa desenvolvido pela ADC, o qual tem atraído cada vez mais pesquisadores. Para o estudo das questões sociais contemporâneas, é singular a relevância do conceito de texto, uma vez que os textos têm efeitos sociais que precisam ser compreendidos. Assim, em relação à ADC, um aspecto fundamental é o método de análise textual, o qual foi desenvolvido em duas etapas até se chegar à Análise de Discurso Crítica propriamente dita: a Linguística Sistêmico-Funcional (LSF), sob influência de Halliday (1976) e a Linguística Crítica (LC), que passa a examinar a relação entre texto, poder e ideologia. Nesse sentido, a ADC pode ser considerada, nas palavras dos autores, uma continuação da LSF e da LC. Contudo, para o âmbito das transformações sociais, é a ADC que propõe um método para o estudo do discurso, uma vez que se dedica à análise de textos, eventos e práticas sociais no contexto sócio-histórico. Portanto, questões da vida social contemporânea, como racismo, sexismo, violência, desigualdades têm na ADC contribuições e debates significativos creditados aos estudos linguísticos.

Um ponto de destaque dessa parte é a observação quanto ao fato de que na $\mathrm{ADC}$ não há um tipo único de perspectiva, mas uma heterogeneidade, mesmo que sempre se possa estabelecer um diálogo entre elas. O ponto decisivo que caracteriza as diferentes abordagens como filiações à ADC é, nas palavras de Teun Van Dijk (1993) citadas pelos autores, 'fazer análise linguística, semiótica ou discursiva' voltada para questões de justiça social. Tanto Van Dijk, filiado à abordagem Sociocognitiva, quanto Faircloug, filiado à abordagem dialéticorelacional, lidam com o discurso e com o texto, e os textos são apresentados como artefatos necessários para o estudo do processo social. Partindo do conceito de texto proposto por Clifford Geertz (1997), os autores esclarecem que para entender os textos é necessário relacioná-los ao contexto social específico e a seus participantes, cujas relações sociais têm significados "que eles conhecem muito mais do que nós que os estudamos" (MAGALHÃES; MARTINS; RESENDE, 2017, p.33). Os 
autores reconhecem a inovação do trabalho teórico do britânico Fairclough, porém, como o método que propoem é de natureza textual na perspectiva da Linguística Sistêmico-Funcional, buscam ainda uma complementação desse método a partir da relação transdisciplinar entre a ADC e a tradição etnográfica, influenciada por Geertz (na linha interpretativista). A abordagem defendida na obra aqui resenhada é a etnográfica-discursiva, considerada passível de dar conta do estudo do discurso como prática social.

A ADC constitui-se em teoria e em método de análise singular na luta social em função do seu arcabouço teórico, da análise do discurso na modernidade posterior e de seu papel na mudança social. O pilar dessa área de estudos é a categoria discurso, cuja abordagem, que remete a Foucault (1987), contribuiu para a marca transdisciplinar no desenvolvimento da Análise de Discurso, tal como destacada por Fairclough. Os autores elencam alguns dos principais aspectos-chave para a compreensão do discurso como uma categoria teórica e como significativa ferramenta no campo da linguagem; dentre esses aspectos, destacam-se conceitos ligados diretamente ao discurso: ordem do discurso, formação discursiva e processo discursivo. O processo discursivo é o que traz a heterogeneidade dos textos e que nos remete, segundo Fairclough, à intertextualidade e à interdiscursividade. É fundamental, portanto, compreender a heterogeneidade dos textos para examinar a fundo o processo discursivo e identificar "os níveis de correspondência entre os textos, o dialogismo que se estabelecem entre eles" (p.42). Assim, o processo discursivo ancora-se em três pilares, conforme formulação de Fairclough (2001): os textos, as práticas discursivas e as práticas sociais. Na Análise de Discurso, os textos podem constituir um corpus - do qual se procede à análise, visando extrair regularidades discursivas. Os textos são resultados de práticas discursivas (o segundo pilar da Análise de Discurso) que recorrem às instituições sociais para se manterem e se reproduzirem. Se o discurso é o pilar da ADC e se no discurso questões relacionadas ao poder e à ideologia interferem, para pesquisadores que se propõem esse caminho de investigação é preciso entender a relação entre essas questões e a linguagem. Para o entendimento da relação entre poder e linguagem, os autores trazem a contribuição de Wodak e Meyer (2009), e de Fairclough (1989), que apontam 'o poder no discurso' e 'o poder por trás do discurso' (MAGALHÃES, MARTINS, RESENDE, 2017, p. 44). E quanto à ideologia, esta tem papel fundamental na luta pelo poder - seja para mantê-lo ou conquistá-lo. Tal conceito, como lembram os autores, é muito debatido nas Ciências Sociais, mas na obra em questão tal conceito não é o da abordagem marxista, mas aquele proposto por Van Dijk (1989), que se baseia em um conceito geral de ideologia que abarca 
também 'sistemas que sustentam e legitimam a oposição e a resistência contra o domínio e a injustiça social' (p.16). Com base nesse ponto, os autores discorrem sobre os modos de operação da ideologia segundo Thompson (1998): a legitimação, a dissimulação, a unificação, a fragmentação e a reificação.

Para tratar do lugar do discurso na modernidade posterior (ou pósmodernidade, expressões usadas para definir a conjuntura cultural que caracteriza o mundo ocidental a partir da última década do século $\mathrm{XX}$ ) marcada pela globalização, os autores tentam fornecer uma visão mais abrangente desse quadro com a apresentação das contribuições dos seguintes autores: Giddens (1997), Sousa Santos (2003), Torfing (1999), Laclau e Mouffe (1985). Após um breve exame dos desdobramentos relacionados à modernidade posterior, é possível para o leitor ou leitora relacionar o discurso com tal conjuntura contemporânea, marcada pelos novos meios eletrônicos e de comunicação, os quais proporcionaram uma série de mudanças significativas na esfera pública, ou seja, "no modo de fazer política, nas identidades, na forma de encarar os direitos humanos e a diversidade" (MAGALHÃES; MARTINS; RESENDE, 2017, p.50). Com essa contextualização, os autores examinam o lugar do discurso considerando os seguintes aspectos específicos: a multiplicidade de vozes; a diversificação dos agentes de poder; a relevância da imagem e da representação na mídia e o controle do poder em disputa permanente.

Sabe-se, a essa altura, que o discurso desempenha papel preponderante na produção, reprodução ou superação de desigualdades ou de relações de dominação. Nesse sentido, podemos falar tanto de mudança social como de mudança discursiva. A relação entre essas duas dimensões da mudança é dialética. E no contexto da modernidade posterior, as desigualdades sociais e os vários tipos de opressão entre sociedades, e no interior de cada uma, ganharam novas configurações, sendo pertinente à $\mathrm{ADC}$ o seu exame. Em seu diálogo com o Realismo Crítico (RC), a ADC possibilita analisar a relação entre linguagem e sociedade, e essa análise discursiva crítica pode possibilitar a materialização discursiva dos problemas sociais, ou seja, realizar a crítica social com base no discurso por meio da análise dos efeitos sociais dos textos, ou seja, seus efeitos causais. Para exemplificarem, com base em Richardson (2007), uma função explanatória para a prática jornalística e sua potencialidade em termos dos efeitos sociais dos textos jornalísticos - a qual é vista por autores como Thompson (1998) como prática ideológica -, os autores trazem uma série de reportagens publicadas pelo Correio Braziliense que culminaram na criação do Projeto GirAção e de outras políticas públicas.

Na parte 2, os autores consideram a etnografia uma abordagem metodológica complementar à Análise de Discurso Crítica e defendem esse posicionamento com 
vários argumentos ao longo dessa parte da obra. Sendo o discurso uma dimensão da prática social, cuja materialidade são textos, esses só serão contextualizados nas práticas por meio de um trabalho de campo. O trabalho de campo possibilita a observação das práticas socioculturais, não apenas a análise textual. É nesse sentido que a etnografia se mostra uma forma de validação da pesquisa, pois vai além da descrição e da explicação textual. As práticas socioculturais constituem um contexto social, o qual precisa ser conhecido e analisado para validar a análise textual, ou seja, para que o estudo do discurso se constitua como uma abordagem crítica. Nesse sentido, a análise de dados precisa ser descritiva (aspectos linguísticos e multimodais), interpretativa e explanatória (aspectos das práticas socioculturais e das identidades dos participantes); os dados são obtidos por meio de observações, entrevistas, artefatos, relatos e diários de participantes. A recomendação dos autores é que seja feito um estudo etnográfico-discursivo do contexto, considerando os seguintes conceitos relacionados: intertextualidade/interdiscursividade, entextualização $e$ recontextualização.

A perspectiva etnográfica-discursiva, por associar métodos etnográficos ao discurso - uma dimensão da prática social -, possui uma grande vantagem pelo fato de relacionar o estudo de textos às práticas sociais, ou seja, é um processo reflexivo baseado em observações e registros, em dados gerados em entrevistas e artefatos coletados no local da pesquisa. O relato etnográfico compõe-se de vários gêneros discursivos, formando uma cadeia de gêneros que vão permitir a análise e investigação de como se dá a articulação entre os momentos que constituem essas práticas sociais, inclusive o discurso. Chouliaraki e Fairclough (1999) analisam contribuições de Harvey (1996), Giddens (1991) e Habermas (1979) quanto à conjuntura da "modernidade tardia" e propõem um novo campo de pesquisa para a ADC, visto compreenderem esse campo 'como parte da reflexividade crescentemente linguística (e mais geralmente social)' de tal conjuntura. À luz dos desafios trazidos pela modernidade tardia, esses autores propõem uma agenda de pesquisa para a $\mathrm{ADC}$, a qual considera problemas que se apresentam na forma de pares dialéticos que buscam explicitar os desdobramentos do discurso nesses novos tempos: colonização-apropriação; globalização-localização; reflexividade-ideologia, identidadediferença. Nesse sentido, práticas discursivas podem ser mobilizadas a serviço da busca de igualdade entre as relações sociais, ou seja, a busca por mudança social, que é uma conjuntura a ser conquistada por atores ou grupos sociais em situações de desigualdade.

A perspectiva ontológica construída por Chouliaraki e Fairclough (1999) para orientar sua abordagem da ADC distingue os seguintes componentes 
ontológicos das práticas sociais: estruturas, práticas e ações sociais, relações sociais, atores sociais, identidades, ideologias, discursos, gêneros discursivos, estilos e textos. Assim, para a investigação desses componentes ontológicos do mundo social, são necessários modelos epistemológicos que permitam construir conhecimentos sobre tais componentes, por meio do método de análise textual da ADC combinado a outros métodos. Em outras palavras, deve-se considerar que alguns métodos são mais adequados que outros, exigindo que haja a reflexão epistemológica anterior a decisões de ordem metodológica. Portanto, a articulação da ADC com a etnografia está nas bases epistemológicas, permitindo a consistência e a coerência com a perspectiva ontológica da $\mathrm{ADC}_{\text {; }}$ isto é, nessa articulação, a relação interdisciplinar da $\mathrm{ADC}$ com as Ciências Sociais efetivamente acontece. No entanto, deve-se ter como ressalva que, tendo em vista a heterogeneidade da etnografia, nem toda prática etnográfica será adequada para a geração e coleta de dados para pesquisas em ADC. As abordagens etnográficas coerentes com a ADC, sendo esta uma prática teórica crítica, serão aquelas que possibilitarão o engajamento com o contexto de pesquisa e com os participantes.

$\mathrm{Na}$ parte 3, os autores examinam as condições e pressupostos do regime democrático nos países contemporâneos, que tem como baluarte do sistema político a liberdade de imprensa. O contexto democrático é marcado pela luta pelos direitos humanos, pela 'consciência de cidadania' e representação das minorias. Nesse sentido, destacam os autores, uma luta pela democracia é uma luta "que se trava também no âmbito do discurso" (p.168). Haja vista a discussão acerca do conceito de esfera pública feita por Fairclough, a qual também é uma discussão sobre as formas de usar a linguagem. É na esfera pública que as questões das minorias são mobilizadas e buscam atendimento. Nessa análise, é possível compreender a relação entre imprensa, minorias (em desvantagem no processo de participação política) e análise do discurso. Os meios de massa são responsáveis pela projeção do discurso dominante para toda a sociedade (como evidenciado no estudo de caso apresentado), mas que também podem ser apropriados como espaço de luta pelos grupos minoritários. No penúltimo capítulo, novamente alguns conceitos-chave são discutidos e diferenciados, principalmente os conceitos de gênero e texto; e gênero e discurso, pois, na perspectiva dos autores, para as pesquisas em ADC alcançarem a explanação de problemas sociais, "a relação entre linguagem e sociedade precisa ser bem compreendida" (MAGALHÃES; MARTINS; RESENDE, 2017, p.203), e para dar conta da natureza interdisciplinar da ADC é necessário muito estudo, além do campo da linguística e do discurso. O último capítulo examina uma questão contemporânea - práticas socioculturais - como é próprio da agenda da ADC: 
a discriminação de gênero (assimetria nas relações de gênero), a violência e as identidades à luz da análise das relações interdiscursivas e intertextuais. "Não há como separar o debate das identidades de questões de discurso" (MAGALHÃES, MARTINS; RESENDE, 2017, p.227)

Análise de discurso crítica: um método de pesquisa qualitativa é uma obra que considera o desafio intelectual, imposto aos pesquisadores, de ampliar a relação entre Ciência Social Crítica e Análise de Discurso Crítica por meio de uma abordagem etnográfica multimetodológica. Assim, a obra contribui para os estudos desse campo de pesquisas e convida à reflexividade quanto à necessidade de tornar coerentes as perspectivas ontológica e epistemológica em ADC. Aos pesquisadores de tradição etnográfica, a obra evidencia o arcabouço que podem encontrar para a análise de dados textuais que lhes permitam mapear as conexões entre escolhas linguísticas de atores sociais ou grupos e categorias sociais amplas, como hegemonia e ideologia. A obra não se dirige apenas a linguistas, mas a todos aqueles que, em seu campo específico, reconhecem o papel do discurso e da linguagem explorados nas esferas sociais para trabalhar interesses hegemônicos ou de luta por mudança social. Embora na atualidade a ADC tenha seu reconhecimento, a maioria das publicações na área são de ordem teórica. Embora a obra aqui resenhada também seja teórica, ela preenche parte da lacuna no que se refere às reflexões metodológicas em ADC, principalmente a sua relação transdisciplinar com a pesquisa etnográfica. Por ser interdisciplinar, a ADC é muito exigente em relação ao aprofundamento teórico. Provavelmente, por esse fato, a discussão e a apresentação de alguns conceitoschave são reiteradas ao longo da obra.

\section{$\overline{\text { REFERÊNCIAS }}$}

CHOULIARAKI, L.; FAIRCLOUGH, N. (1999). Discourse in late modernity. Rethinking critical discourse analysis. Edimburgo: Edinburgh University Press.

FAIRCLOUGH, N. (1989). Language and power. Londres/Nova York: Longman.

FAIRCLOUGH, N. (2001). Discurso e mudança social. Coordenação de tradução, revisão e prefácio à edição brasileira: I. Magalhães. Brasília: Editora Universidade de Brasília.

FOUCAULT, M. (1987). A arqueologia do saber. 3.ed. Trad. L. F. B. Neves. Rio de Janeiro: Forense-Universitária.

GEERTZ, C. (1997). O saber local. Trad. V. M. Joscelyne. Petrópolis: Vozes. 
GIDDENS, A. (1991). Modernity and self-identity. Self and society in the late modern age. Cambridge: Polity Press.

GIDDENS, A. (1997). Modernidade e identidade pessoal. Trad. M. V. de Almeida. Oeiras, Portugal: Celta.

HABERMAS, J. (1979). Communication and the evolution of society. Boston: Beacon Press.

HARVEY, D. (1996). Justice, nature and the geograpby of difference. Londres: Blackwell.

LACLAU, E.; MOUFFE, C. (1985). Hegemony and socialist strategy. Londres: Verso.

MAGALHÃES, I. (2004). Teoria crítica do discurso e texto. CALDAS-COULTHARD, C. R.; FIGUEIREDO, D. de C. (Org.). Linguagem em (Dis)curso, Palhoça, v. 4, Especial, p. $113-31$.

MAGALHÃES, I. (2005). Critical discourse analysis and the semiotic construction of gender identities. D.E.L.T.A., 21: Especial: 179-205. Org. Magalhães, I. \& Rajagopalan, K.

MAGALHÃES, I. (2010). Discurso e identidades - exotismo e domínio violento. Cadernos de Linguagem e Sociedade, Brasília, v. 11, n. 1, p. 13-37.

MAGALHÃES, I. (2016). Crítica Social e Discurso. In: FERREIRA, R. R.; RAJAGOPALAN, Kanavillil (Orgs.). Um Mapa da Crítica nos estudos da linguagem e do discurso. Campinas, SP: Pontes Editores.

RAJAGOPALAN, K. (2013). Prefácio. In: SATO, Denise T. B.; JUNIOR, J.R.L. B. Contribuições da análise de discurso crítica no Brasil: uma bomenagem aà Izabel Magalbães. Coleção Linguagem e Sociedade, Vol. 5. Campinas, SP: Pontes Editores., 2013.

RAMALHO, V.; RESENDE, V. (2011). Análise de discurso (para a) crítica: o texto como material de pesquisa. Campinas, SP: Pontes Editores.

RESENDE, V.; RAMALHO, V. (2006). Análise de discurso crítica. São Paulo: Contexto.

RICHARDSON, J. E. (2007). Analysing newspapers. An approach from Critical Discourse Analysis. Hampshire/Nova York: Palgrave Macmillan.

SATO, Denise T. B.; JUNIOR, J.R.L. B. (2013). Contribuições da análise de discurso crítica no Brasil: uma bomenagem à Izabel Magalbães. Coleção Linguagem e Sociedade, Vol. 5. Campinas, SP: Pontes Editores. 
SOUSA SANTOS, B de. (2003). Por uma concepção multicultural de direitos humanos. In: SOUSA SANTOS, B de. (Org.). Reconbecer para libertar. Os caminhos do cosmopolitismo multicultural. Rio de Janeiro: Civilização Brasileira. p. 427-446.

THOMPSON, J. B. (1998). Ideologia e cultura moderna. Teoria social crítica na era dos meios de comunicação de massa. Trad. P. A. Guareschi et al. Petrópolis, RJ: Vozes.

TORFING, J. (1999). New theories of discourse. Laclau, Mouffe and Zizek. Oxford/Malden: Blackwell.

WODAK, R.; MEYER, M. (2009). Critical Discourse Analysis: history, agenda, theory and methodology. In: WODAK, R.; MEYER, M. (Org.) Methods of Critical Discourse Analysis. 2. ed. Londres: Sage. p. 1-33.

Recebido: $12 / 10 / 2017$

Aceito: 25/02/2019

Publicado: 29/03/2019 